Dr Steven Ratuva is a senior lecturer in Auckland University's Centre for Pacific Studies.

\section{Pain, suffering but a ray of hope for Fiji’s future}

State of Suffering: Political Violence and Community Survival in Fiji, by Susanna Trnka. Ithaca, New York: Cornell University Press, 2008, 214 pp. ISBN 9780807476989

$\mathrm{T}$ HE DISCOURSE on Fiji's embattled political history has often been the domain of historians, political scientists and economists and every now and then, the intellectual monotony is broken by streaks of intellectual freshness, which provide new prisms through which we can visualise the complex socio-political reality of the Fiji society. The book, State of Suffering: Political Violence and Community Survival in Fiji by Auckland University anthropologist Susanna Trnka, does just that.

The ethnographic approach shifts analysis away from the conventional broad-sweeping political narrative that political scientists and historians

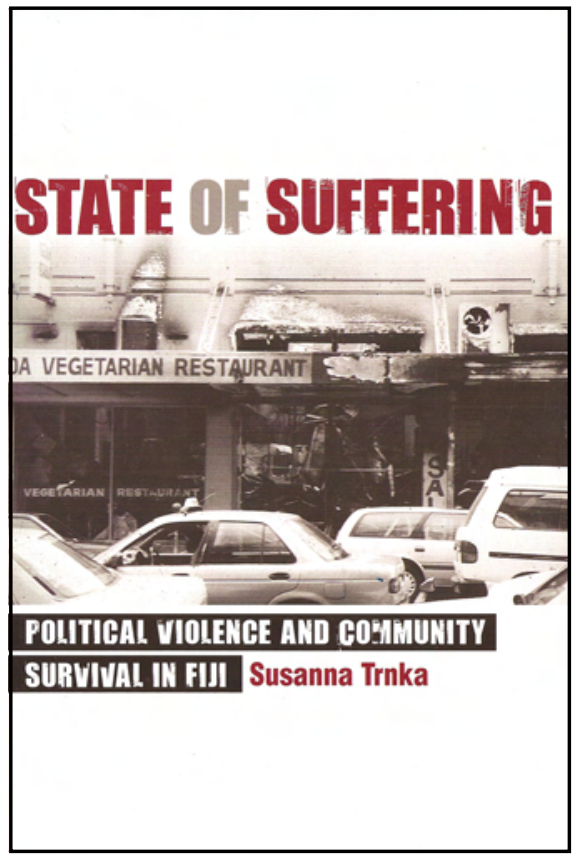

tend to thrive on and captures in a meticulous anthropological fashion, the living experiences and consciousness of individuals and communities, embroiled in a survival game amid the political chaos of the 2000 coup.

However, the absence of the role of the media in the book is quite conspicuous because, over the years, the media has been instrumental in reinforcing stereotypes, constructing prejudices and inflaming tension. The pattern of reporting between IndoFijian and indigenous Fijian journalists was quite apparent. There were indigenous Fijian reporters who were 'embedded' with the rebels and took 
a coup sympathy and justificatory stance and, on the other hand, many Indo-Fijian journalists took a 'victimhood' stance and were geared towards reporting the excesses of the coup.

The book is based on Trnka's fieldwork in Fiji during the 2000 coup, Fiji's third since independence from Britain in 1970. The 2000 coup, like the first two coups in 1987 , were inspired by indigenous ethnonationalists who feared that their claim to 'paramountcy of Fijian interest' was going to be undermined by Indo-Fijian political hegemony after the first Indo-Fijian Prime Minister, Mahendra Chaudhry, was elected in 1999. The shift in the political gravity away from indigenous dominance provided the fertile ground for 'ethnic entrepreneurs', as sociologists would say, who used the ethnic card to agitate against Chaudhry.

Not all of them were committed ethno-nationalists. George Speight,the self-styled leader of the 2000 coup, was never an indigenous rights activist but an ambitious businessman whose attempt to build a fortune from the lucrative mahogany industry, after making a deal with an American company, was thwarted after his removal as chair of the board in charge of mahogany harvesting by Chaudhry. There were also business people who feared that Chaudhry, a unionist, would be anti-business and would make them accountable for their tax evasion schemes. Chaudhry's authoritarian and uncompromising style of leadership won himself many political enemies and further reinforced in the minds of the indigenous Fijians some existing negative stereotypes such as 'arrogance' and 'selfishness' about Indo-Fijians. These played well into the ethnonationalist undercurrents.

While the book talked about daily anxiety and fear of the Fiji citizens created by the street rumour mongering machine, the media played a crucial role in magnifying this. Simply reporting about the rumours made people believe them and this intensified their fear. There was always fear of Speight's group in Parliament 'marching down' to town. Every day, the rumours were deliberately planted by Speight's psychological warfare machine, targeted at the military as well as civilians, as a means of inciting violence, psychological control and inducing submission. These were reinforced by Speight's daily interviews, news of burning, violence and theft and reporting of happenings in Parliament where the hostages (members of the ruling party) were still being held.

The Fijian radio stations repeatedly played nationalistic speeches by nationalist leaders and sermons 
by Methodist church leaders. This fired up anti-Indian and anti-heathen feelings and provided the moral justifications for the violence, pain and suffering inflicted on the Indo-Fijian community. The media provided the link between the world of the coup makers and the community at large. While it contributed to enhancing fear, it also acted as a reassuring agent. It provided the avenue for dialogue, for peace building and free expression. It provided the sociopsychological therapy by connecting people and making them share their pain and suffering in a situation of hopelessness.

This book captures some of the deeper psychological, socio-cultural and spiritual dilemmas faced by the Indo-Fijian community in Fiji as they struggled to maintain a sense of collective security, sanity, selfpreservation and perpetuity in the face of predatory ethno-nationalism. The coup spawned a number of interrelated paradoxical dualities, which were to shape the subsequent trajectory of political development in Fiji in a fundamental way. These included national impressions of 'normalcy' versus individual pain, multiculturalism versus ethnic fragmentation and stereotypes of Fijian 'savagery' versus indigenous Fijian sense of accommodation, among others.
The author weaves her narrative through the Fiji time and space in a methodological way as she negotiates her way across the minefields of violence, pain, identity crisis, rumours, crisis of legitimacy and regime change spawned by the 2000 coup. She is able to weave together strands of individual experiences of pain and suffering of the victims of violence with collective communal fear of the Indo-Fijian community. The notions of pain and suffering are central to the book: how they are inflicted, experienced, responded to at the individual, community and national levels and their role in shaping the political and ethnic psyche of a community as it struggled to come to terms with its survival in a politically hostile environment.

One of the significant aspects of the book is how it lays bare some deep ethnic stereotype of indigenous Fijians by Indo-Fijians. In everyday discourse Fijians are cast in degrading images such as 'savage' 'animals', ‘jungali’ (bushmen). While these stereotypic categorisations are more intense and direct in the private domain, they are less explicit at the public and political sphere where politicians rhetoricise about multiculturalism while trying at all cost to conceal their deeper prejudices. These stereotypes are even more subtle but 
still identifiable in scholarly works by some Indo-Fijian writers who problematise indigenous Fijians as instigators of political instability and barriers to Fiji's economic development because of their 'outdated' culture and 'regressive' landowning system.

Some books on the experiences of Indo-Fijians in Fiji portray indigenous people only as insignificant 'jungali' entities who pose a barrier to the march of progress and enlightenment of Indo-Fijians as bearers of the grand ancient Indus civilisation that is far superior in culture and morality to the Oceanic 'Kaiviti' (Fijian term used to refer to indigenous Fijians).

On the other hand, however, indigenous Fijians stereotype IndoFijians in equally degrading terms, often as selfish, untrustworthy, cunning and scheming, the same way that Jews and other business groups are stereotyped in other parts of the world. Their moral character as nonChristian 'heathens' is a national scourge to be eradicated. This perception extends to politics where it is believed that the 'Kaidia' (Fijian word for Indian) is not to be trusted to run the government because they will use it to deprive Fijians of their land and indigenous rights.

A common assumption is that if you give Indo-Fijians an inch they will take a mile. An indigenous Fijian parliamentarian once said in Parliament a few years ago that 'Indians are like weeds...they grow everywhere'. These stereotypes have been used by ethnic entrepreneurs as convenient mobilisation tools for ethno-nationalism.

When stereotypes are repeated over and over again the constructed images become 'real' in people's cultural sub-consciousness and the target group even end up assimilating, 'believing' and playing out these images thus further reinforcing the constructed behavioural characteristics. It is quite common for indigenous Fijians to lament about their lack of business acumen and the need to emulate Indo-Fijians, yet they proudly articulate their physical prowess in rugby and war as part of their identity.

A significant paradox is that by focusing only on the Indo-Fijian victims of the coup, the book fails to recognise that there were also indigenous Fijian victims whose suffering were not as intensively highlighted. Some were physically assaulted by Speight's thugs and some had their properties violated. Later when the tide turned against the rebels after the military took control of power, hundreds of indigenous coup supporters were arrested and beaten up 
in public and many sustained very serious injuries. The pain inflicted on the indigenous Fijian community by the military was unprecedented. As a result of this, many indigenous Fijians began to see the military, which they once saw as a reliable political ally as in the 1987 coup, as an antiindigenous institution and a tool of Indo-Fijian political conspiracy.

This raises fundamental questions about ethnographic research in a conflict situation. It is always important to understand competing discourses to avoid perception of partiality. While this is of course not intended, the latent and perceived political message of the book can be dangerously simplistic: innocent and helpless Indo-Fijians being clobbered mercilessly by naturally ferocious and vicious indigenous Fijians. Herein lies a major dilemma for ethnographic researchers trying to negotiate their way through the political trenches and ideological minefields in a conflict situation.

Perhaps to avoid some of these perceptions, the book could have also done an analysis of the coup situation from the point of view of indigenous Fijians. How did they conceptualise Indo-Fijians? What types of stereotypes did they hold? What were the underlying assumptions of these stereotypes. Often stereotypes between two groups are dialectic in nature-there are usually two negatives negating and 'balancing' each other out. External perception by others can shape self-perception of another.

There is also no mention of the symbolic and functional role of the military in relation to ethno-nationalism. Did the military symbolise a 'painkilling' intervention as they flushed out the perpetrators of pain and suffering and made the situation safer for Indo-Fijians? Many of the perpetrators of violence were not the 'average' Fijian or even die-hard anti-Indian ethno-nationalists but were unemployed youths, some with criminal records who took advantage of the situation to express their socioeconomic frustrations by scapegoating Indo-Fijians.

Nevertheless, despite this, the book is a very valuable contribution to the endless debates on ethnic relation and political conflict in Fiji. By unearthing the experiences and sentiments of ordinary people in a confusing and psychologically oppressive situation, the book fills a major void in contemporary Fijian socio-political discourse. It captures in a succinct way the dilemma of a Diaspora, caught up in colonially created circumstances, which they become victims of. Despite the pain and suffering portrayed in the book, 
it also provides a ray of hope for interethnic engagement by documenting instances of indigenous Fijian villagers providing refuge for some Indo-Fijians and saving them from marauding thugs.

In a symbolic and functional way, these actions show the existing vast reserve of goodness and potential for interethnic engagement and integration in Fiji. Herein lies Fiji’s future.

\section{South Pacific} Books

NZ's only specialist Maori \& Pacific bookshop

Located inside the Works Hair Salon

142 Williamson Avenue Grey Lynn Auckland City

(opposite Occam Cafe \& Foodtown)

\section{Open Wednesday to Friday}

$10 \mathrm{am}-3 \mathrm{pm}$

sales@southpacificbooks.co.nz

South Pacific Books Ltd

093600340

www.southpacificbooks.co.nz 